\title{
Gastrointestinal stromal tumors (GISTs): role of CD 117 and PDGFRA Golgi-like staining pattern in the recognition of mutational status
}

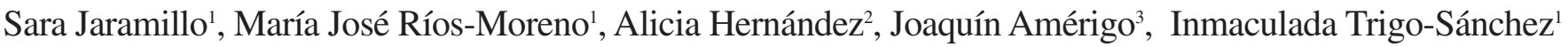 \\ and Ricardo González-Cámpora ${ }^{1}$
}

Department of Pathology. ${ }^{1}$ Hospital Universitario Virgen Macarena. Seville, Spain. ${ }^{2}$ Hospital Infanta Cristina. Badajoz, Spain. ${ }^{3}$ Hospital Torrecárdenas. Almería, Spain

\begin{abstract}
Aims: to determine whether potential correlations between CD117 and PDGFRA might serve as an indication for targeted therapies.

Material and methods: immunohistochemical expression of CD117 and PDGFRA was evaluated in 99 paraffin-embedded GISTs in conjunction with KIT and PDGFRA mutational status.

Results: CD117-positive staining was noted in 93 out of 99 cases. The predominant staining pattern was cytoplasmic, either with or without membrane accentuation; in $44.5 \%$ of cases, a clear Golgi-like pattern was evident. Correlations were found between KIT mutation and both CD117 expression ( $p=0.006$ ) and Golgi-like pattern $(p=0.026)$. Cytoplasmic PDGFRA-positive staining was detected in $87 \%$ of cases, both with and without membrane accentuation; in 8\% cases an evident Golgi-like staining pattern was observed. A significant correlation was noted between PDGFRA mutations and Golgi-like staining pattern $(p=0.001)$. Moreover, 95\% of PDGFRA-positive GISTs were also CD117positive, suggesting that expression of the two markers is not mutually exclusive; most of these had mutations in KIT exon 11. PDGFRA-positive/CD117-negative tumors had mutations in PDGFRA, mainly in exon 18. PDGFRA-negative/CD117-negative staining was observed in $15 \%$ of cases, all of which displayed mutations in KIT exon 11. CD117-positive/PDGFRA-negative cases were characterized by mutations in KIT, mainly in exon 11 .

Conclusions: CD117 and PDGFRA staining are not exclusive, and the presence of a Golgi-like staining pattern for either, whilst not pathognomonic, is highly suggestive of KIT and PDGFRA mutated GISTs, respectively, and may be used with some reservations as an alternative indication for prescribing targeted therapies.
\end{abstract}

Key words: Gastrointestinal stromal tumors. GISTs, CD117. PDGFRA. Mutational status. Golgi-like staining pattern.

This research was supported by a grant from Novartis, Spain.

Received: $10-10-11$

Accepted: 14-11-11.

Correspondence: Ricardo González-Cámpora. Department of Pathology.. Hospital Universitario Virgen Macarena. Avda. Dr. Fedriani, s/n. 41009 Sevilla, Spain.

e-mail: rcampora@us.es
Jaramillo S, Ríos-Moreno MJ, Hernández A, Amérigo J, Trigo-Sánchez I, González-Cámpora R. Gastrointestinal stromal tumors (GISTs): role of CD 117 and PDGFRA Golgi-like staining pattern in the recognition of mutational status. Rev Esp Enferm Dig 2012; 104: 128-133.

\section{INTRODUCTION}

Gastrointestinal stromal tumors (GISTs) are mesenchymal tumors of the gastrointestinal tract that differentiate towards interstitial cells of Cajal or their precursors; they are generally KIT (CD117)-positive, and display KIT or PDGFRA gene mutations $(1,2)$. More occasionally they may display mutations in others genes, including BRAF (3) and $S D H B$ (4). These tumors have recently aroused particular interest due to their good response to new targeted therapies $(5,6)$.

Immunohistochemical expression of CD117 has been considered one of the most sensitive markers for diagnosing both mutant and wild-type GISTs $(2,7)$, but little is known regarding its role in predicting mutational status (8-10). PDGFRA staining, by contrast, is often held to be non-specific, ubiquitous and technically deficient, with no role in the diagnosis of GIST $(7,9,11,12)$. However, recent studies have shown that a Golgi-like staining pattern for either CD117 or PDGFRA may be predictive of mutational status $(7-9,11,12)$.

In this study, immunohistochemical expression of CD117 and PDGFRA was evaluated in 99 paraffin-embedded GISTs in conjunction with KIT and PDGFRA mutational status, in order to determine whether potential correlations between the two might serve as an indication for targeted therapies.

\section{MATERIAL AND METHODS}

\section{Patient selection and clinical features}

Representative samples were selected from a set of formalin-fixed, paraffin-embedded surgical specimens obtained 
from 99 GISTs. Samples were from patients undergoing surgery at the Hospital Universitario Virgen Macarena (Seville) and Hospital Torrecárdenas (Almería) over a 20year period (1989-2009). Tumor sample collection was approved by the Hospital Ethical Committees. Hematoxylineosin-stained slides were reviewed and the pathological diagnosis was confirmed by tumor location, morphology, immunostaining for CD117 and molecular analysis of KIT/PDGFRA status. Tissue microarrays (TMAs) were constructed using a TMADesigner ${ }^{\circledR}$ version 1.1 manual tissue arrayer (Alphelys, Plaisir, France); five $0.6 \mathrm{~mm}$ cores were taken from each paraffin-embedded sample.

The following clinical and pathological data were accessed: patient age and gender, tumor location (gastric, small and large bowel, extragastrointestinal), tumor size, histological type (spindle, epithelioid, mixed), and mitotic index in 50HPF.

\section{Immunohistochemical analysis}

For immunohistochemical analysis, $5 \mu \mathrm{m}$ serial sections were stained with a panel of antibodies: CD117 (Diagnostic Biosystem, CA; prediluited), PDGFRA (Santa Cruz Biotechnology, USA; dilution 1:100) using the streptavidinbiotin-peroxidase complex technique. Negative (primary antibody replaced by normal horse serum) and positive controls (sections of a human breast cancer) were included in each slide run. All controls yielded satisfactory results. Specimens with diffuse or focal immunostaining were considered positive. Tumors with $\leq 5 \%$ of positive cells were considered negative. Staining for individual antibodies was classed as either positive or negative.

\section{DNA isolation and molecular analysis}

One selected paraffin block was chosen for molecular analysis; DNA was isolated using a QIAmp DNA FFPE Tissue kit according to manufacturer's instructions (Quiagen, Hilden, Germany). KIT exons 9, 11, 13 and 17 and PDGFRA exons 12 and 18 were amplified by polymerase chain reaction (PCR). The PCR reaction was carried out using a Taq PCR Master Mix (Quiagen, Hilden, Germany) including 0.1-1 $\mu \mathrm{g}$ of extracted DNA and $0.2 \mu \mathrm{M}$ forward and reverse primers to a total volume of $30 \mu \mathrm{L}$. Primers and experimental conditions are shown in table I. PCR products were examined using a QuiAXcel DNA High Resolution kit (Quiagen, Hilden, Germany) and sequencing was carried out with an automated analyzer (ABI PRISM 3130xl Genetic Analyzer, Applied Biosystem, USA). KIT and PDGFRA sequencing results were compared with gene sequences in the NCBI genebank.

\section{Statistical analysis}

Clinical and immunohistochemical data were analyzed using the SPSS for Windows, version 17.0 software package
Table I. Primers are presented in $5^{\prime}$ to $3^{\prime}$ orientation with the coding strand labeled $(+)$ and the noncoding strand labeled (-). Tm and cycle number correspond to the linear part of the amplification

\begin{tabular}{|c|c|c|c|}
\hline & Primers & Strand & $\begin{array}{l}\text { Condition } \\
(T m ; \\
\left.\text { cycle } n^{\circ}\right)\end{array}$ \\
\hline KIT exon 9 & $\begin{array}{l}\text { TCCTAGAGTAGTAAGCCAGGGCTT } \\
\text { TGGTAGACAGAGCCTAAACATCC }\end{array}$ & + & $56^{\circ} \mathrm{C}, \times 40$ \\
\hline KIT exon 11 & $\begin{array}{l}\text { CCAGAGTGCTCTATAGACTG } \\
\text { AGCCCCTGTTTCATACTGAC }\end{array}$ & + & $56^{\circ} \mathrm{C}, \times 40$ \\
\hline KIT exon 13 & $\begin{array}{l}\text { GACATCAGTTTGTCAGTTG } \\
\text { GCAAGAGAGAACAACAG }\end{array}$ & + & $56^{\circ} \mathrm{C}, \times 40$ \\
\hline KIT exon 17 & $\begin{array}{l}\text { GTGAACATCATTCAAGGCG } \\
\text { TTACATTATGAAAGTCACAGG }\end{array}$ & $\begin{array}{l}+ \\
-\end{array}$ & $56^{\circ} \mathrm{C}, \times 40$ \\
\hline $\begin{array}{l}\text { PDGFRA } \\
\text { exon } 12\end{array}$ & $\begin{array}{l}\text { TCCAGTCACTGTCCTGCTTC } \\
\text { GCAAGGGAAAAGGGAGTCTT }\end{array}$ & + & $56^{\circ} \mathrm{C}, \times 40$ \\
\hline $\begin{array}{l}\text { PDGFR } \\
\text { exon } 18\end{array}$ & $\begin{array}{l}\text { ACCATGGATCAGCCAGTCTT } \\
\text { TGAAGGAGGATGAGCCTGACC }\end{array}$ & $\begin{array}{l}+ \\
-\end{array}$ & $56^{\circ} \mathrm{C}, \times 40$ \\
\hline
\end{tabular}

(SPSS Inc., Chicago, IL, USA). Chi-square tests were used to analyze associations between variables. A p-value of less than 0.05 was considered statistically significant.

\section{RESULTS}

\section{Clinical features and mutational status}

All tumors displayed clinical/pathological features consistent with GIST, and expressed CD117 and/or harbored KIT/PDGFRA mutations. The median age was 64 years (range: 13-87), and samples were from 51 (51.5\%) males and $48(48.5 \%)$ females. Forty-eight $(48.5 \%)$ tumors originated in the stomach, $36(36.1 \%)$ in the small bowel, 7 $(7.2 \%)$ in the large bowel and $8(8.2 \%)$ in extragastrointestinal locations in the mesentery and omentum. Mean tumor diameter was $7.65 \mathrm{~cm}$ (range 1.0-25 cm). Tumor diameter was less than $2 \mathrm{~cm}$ in $60(60.6 \%)$ cases, between 2 and $5 \mathrm{~cm}$ in 31 cases $(30.9 \%)(31.3 \%)$, between 5 and $10 \mathrm{~cm}$ in 6 cases $(6.1 \%)$ and over $10 \mathrm{~cm}$ in 2 cases $(2.1 \%)$. Histologically, 78 (79.2\%) neoplasms were of spindle type, $15(15.1 \%)$ of epithelioid type and $5(5.1 \%)$ showed mixed cytomorphology. Mitotic counts ranged from 1 to 60 in 50 high power fields (50HPF): 54 samples (55\%) displayed $<2$ mitotic counts; $17(17 \%)$ between 2 and 5; and $28(28 \%)>5$.

Molecular analysis revealed KIT mutation in 68/99 (69\%) cases, PDGFRA mutation in 11/99 (11\%) and wild 


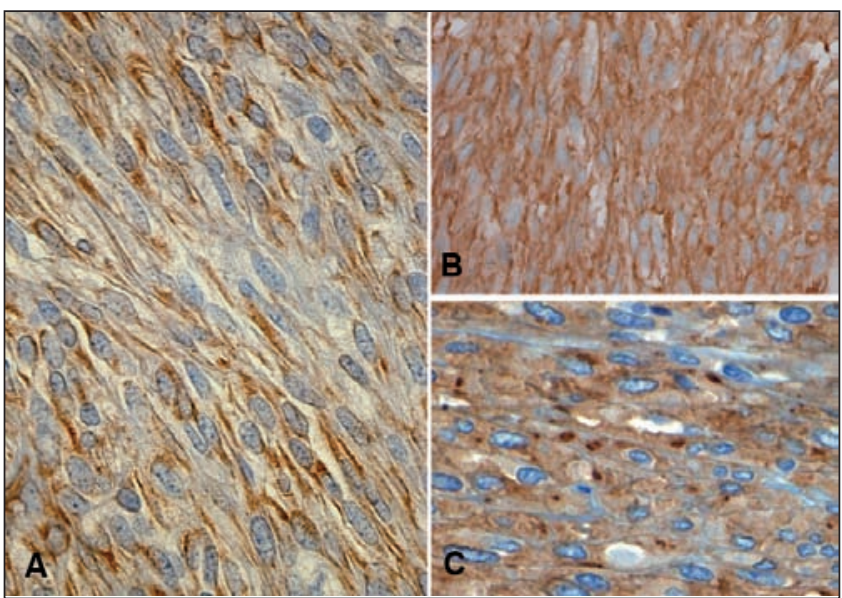

Fig. 1. GIST. CD117 staining pattern. A. Cytoplasmic staining. B. Cytoplasmic with membrane accentuation. C. Cytoplasmic and paranuclear Golgi-like staining.

type (wt) KIT/PDGFRA in 20/99 (20\%). Among cases with KIT mutation, 64/68 (94\%) had exon 11 mutations and 4/68 $(6 \%)$ exon 9 mutations. There were no cases of exon 13 or exon 17 mutation. Among cases with PDGFRA mutation, 9/11 (82\%) had mutations of exon 18 and 2/11 (18\%) of exon 12. All CD117-negative cases had KIT (3, exon 11) or PDGFRA (2, exon 18; 1, exon 12) mutations.

\section{Immunohistochemical analysis of CD117 and PDGFRA}

A total of 93 of the 99 cases studied (94\%) stained positive for CD117. Distribution was as follows: stomach, 43/48 (89.6\%), small bowel, 35/36 (97.2\%), large bowel $7 / 7(100 \%)$, extragastrointestinal 8/8 (100\%). Staining was mostly diffuse, but occasional cases displayed focal staining. The staining pattern was predominantly cytoplasmic, either with or without membrane accentuation; in 49/99 $(49.5 \%)$ cases, a remarkable cytoplasmic dot-like or Golgi-like pattern was evident (Fig. 1). CD117-staining patterns as a function of mutational status are shown in table II. A clear correlation was noted between KIT mutation and both CD117 expression $(\mathrm{p}=0.006)$ and Golgi-like pattern $(\mathrm{p}=$ 0.026) (Table II; Fig. 2A). Although most tumors with a Golgi-like pattern had mutations in exon 11, three cases had mutations in exon 9 (Table II). Of the six cases staining negative for CD117 (Fig. 2), 3 had mutations in KIT and the other 3 in PDGFRA (Table II).

Eighty-six of 99 cases (87\%) stained positive for PDGFRA, with the following distribution: stomach 42/48 (87.5\%), small bowel 30/36 (83\%), large bowel 7/7 (100\%) and extragastrointestinal 7/8 (87.5\%). Staining was mostly diffuse and cytoplasmic, either with or without membrane accentuation; in 7/86 (8\%) cases a notable Golgi-like staining pattern was observed (Fig. 3). Although no significant correlation was found between diffuse cytoplasmic staining
Table II. Mutational status and CD117 expression patterns

\begin{tabular}{|c|c|c|c|c|c|c|}
\hline \multicolumn{2}{|l|}{ CD117 } & \multicolumn{2}{|l|}{ KIT } & \multicolumn{2}{|c|}{ PDGFRA } & $\begin{array}{l}\text { WT } \\
\text { KIT/PDGFRA }\end{array}$ \\
\hline \multirow{3}{*}{\multicolumn{2}{|c|}{$\begin{array}{l}\text { Cytoplasmic/Membrane } \\
\text { Golgi pattern } \\
\text { Negative }\end{array}$}} & \multirow{3}{*}{\multicolumn{2}{|c|}{$\begin{array}{l}29 / 68(43 \%) \\
36 / 68(53 \%) \\
3 / 68(4 \%)\end{array}$}} & \multirow{3}{*}{\multicolumn{2}{|c|}{$\begin{array}{l}5 / 11(45 \%) \\
3 / 11(27.5 \%) \\
3 / 11(27.5 \%)\end{array}$}} & \multirow{3}{*}{$\begin{array}{l}10 / 20(50 \%) \\
10 / 20(50 \%) \\
0 / 20(0 \%)\end{array}$} \\
\hline & & & & & & \\
\hline & & & & & & \\
\hline \multirow[t]{2}{*}{ CD117 } & KIT & & KIT & & PDGFRA & PDGFRA \\
\hline & Exon 11 & & Exon 9 & & Exon 18 & Exon 12 \\
\hline $\begin{array}{l}\text { Cytoplasmic/ } \\
\text { Membrane }\end{array}$ & \multicolumn{2}{|c|}{ 28/64 (43.7\%) } & \multicolumn{2}{|c|}{$1 / 4(25 \%)$} & $4 / 9(44.5 \%)$ & $1 / 2(50 \%)$ \\
\hline Golgi pattern & \multicolumn{2}{|c|}{$33 / 64(51.6 \%)$} & \multicolumn{2}{|c|}{$3 / 4(75 \%)$} & $3 / 9(33.3 \%)$ & $0 / 2(0 \%)$ \\
\hline Negative & \multicolumn{2}{|c|}{$3 / 64(4.7 \%)$} & $0 / 4(0 \%)$ & & $2 / 9(22.2 \%)$ & $1 / 2(50 \%)$ \\
\hline
\end{tabular}

and mutational status, there was a significant correlation between PDGFRA mutations and the Golgi-like staining pattern $(\mathrm{p}=0.001)$ (Table III). No PDGFRA-negative cases had PDGFRA mutations.

Interestingly, 95\% of PDGFRA-positive GISTs were also CD117-positive (82/86), indicating that expression of the two markers is not mutually exclusive (Table IV). Most CD117-positive/PDGFRA-positive cases had mutations in KIT exon 11 (54/82, 66\%), although the correlation was not statistically significant. Half of the PDGFRA-positive/ CD117-negative tumors (4/86) had mutations in PDGFRA, mainly in exon 18 (2/4). All PDGFRA-negative/CD117negative (2/2) tumors had KIT exon 11 mutations. Finally, CD117-positive/PDGFRA-negative had KIT mutations (8/11), mainly involving exon 11 (64\%) (Table IV).

\section{DISCUSSION}

The term "stromal tumors" was coined by Clark and Mazur in 1983 (13), to designate a subgroup of gastric mesenchymal tumors that lacked both smooth muscle and Schwannian differentiation; the term was subsequently extended to include other, similar, digestive-tract tumors, and the acronym GIST started to become widely used (14). Current interest in these tumors largely reflects their good response to kinase-inhibitor therapy (15). Although the clinical response to imatinib is known to depend on mutational status $(6,16-19)$, GISTs are routinely diagnosed by conventional histology in conjunction with immunohistochemical demonstration of KIT receptor (CD117) expression (2), since other unrelated neoplasms have similar phenotypes or genotypes (20,21). In normal gastrointestinal-tract wall, positive staining for CD117 is only observed in the interstitial cells of Cajal or, more occasionally, in mast cells scattered throughout the thickness of the wall (2). In GISTs, positive staining may be diffuse, patchy or focal, and CD117-negative staining rates range between 2.2 and $8 \%$ depending on the characteristics of the tumors stud- 


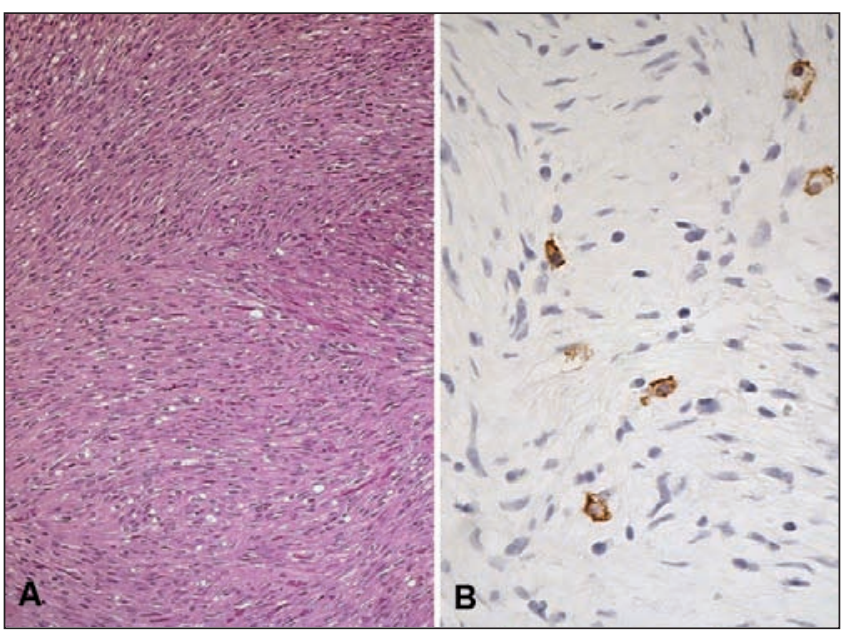

Fig. 2. GIST. CD117-negative. A. Spindle cell neoplasm. B. Negative staining in tumor cell with internal positive control in mast cells.

ied (11,12,22-24). Staining for CD117 is generally easy to evaluate. Positivity typically appears as diffuse cytoplasmic staining, sometimes with a varying degree of membrane accentuation; in some cases, however, focal Golgi-like staining may be observed (20). This Golgi-like staining pattern has aroused interest over recent years, because it has been linked to mutated KIT molecules accumulation $(11,25)$; for that reason, it has been proposed as a possible marker for KIT mutations, and therefore as an indicator for imatinib therapy (9-11). Here, $94 \%$ of tumors (93/99) were CD117-positive, and a Golgi-like staining pattern was observed in $49.5 \%$ (49/99). Although most of these tumors (73\%) had KIT mutations (36/49), the Golgi-like pattern was also observed in wt KIT/PDGFRA tumors (10/49) and in PDGFRA-mutated tumors (3/49), indicating that expression of the markers is not mutually exclusive, as asserted by Miselli et al. (9). Emile et al. (8) reported a significant

Table III. Mutational status and PDGFRA expression pattern

\begin{tabular}{|c|c|c|c|c|c|c|}
\hline PDGFRA & \multicolumn{3}{|c|}{ KIT } & \multicolumn{2}{|c|}{ PDGFRA } & $\begin{array}{l}\text { wt } \\
\text { KIT/PDGFRA }\end{array}$ \\
\hline \multirow{3}{*}{\multicolumn{2}{|c|}{$\begin{array}{l}\text { Cytoplasmic/Membrane } \\
\text { Golgi pattern } \\
\text { Negative }\end{array}$}} & \multirow{3}{*}{\multicolumn{2}{|c|}{$\begin{array}{l}57 / 68(84 \%) \\
1 / 68(1.5 \%) \\
10 / 68(15.5 \%)\end{array}$}} & \multirow{3}{*}{\multicolumn{2}{|c|}{$\begin{array}{l}7 / 11(64 \%) \\
4 / 11(36 \%) \\
0 / 11(0 \%)\end{array}$}} & $15 / 20(75 \%)$ \\
\hline & & & & & & $2 / 20(10 \%)$ \\
\hline & & & & & & $3 / 20(15 \%)$ \\
\hline \multirow[t]{2}{*}{ PDGFRA } & \multirow{2}{*}{\multicolumn{2}{|c|}{$\begin{array}{l}\text { KIT } \\
\text { Exon } 11\end{array}$}} & \multirow{2}{*}{\multicolumn{2}{|c|}{$\begin{array}{l}\text { KIT } \\
\text { Exon } 9\end{array}$}} & PDGFRA & PDGFRA \\
\hline & & & & & Exon 18 & Exon 12 \\
\hline $\begin{array}{l}\text { Cytoplasmic/ } \\
\text { Membrane }\end{array}$ & \multicolumn{2}{|c|}{$54 / 64(84 \%)$} & \multicolumn{2}{|c|}{$3 / 4(75 \%)$} & $6 / 9(67 \%)$ & $1 / 2(50 \%)$ \\
\hline Golgi pattern & \multirow{2}{*}{\multicolumn{2}{|c|}{$\begin{array}{l}1 / 64(2 \%) \\
9 / 64(14 \%)\end{array}$}} & \multirow{2}{*}{\multicolumn{2}{|c|}{$\begin{array}{l}0 / 4(0 \%) \\
1 / 4(25 \%)\end{array}$}} & $3 / 9(33 \%)$ & $1 / 2(50 \%)$ \\
\hline Negative & & & & & $0 / 9(0 \%)$ & $0 / 2(0 \%)$ \\
\hline
\end{tabular}

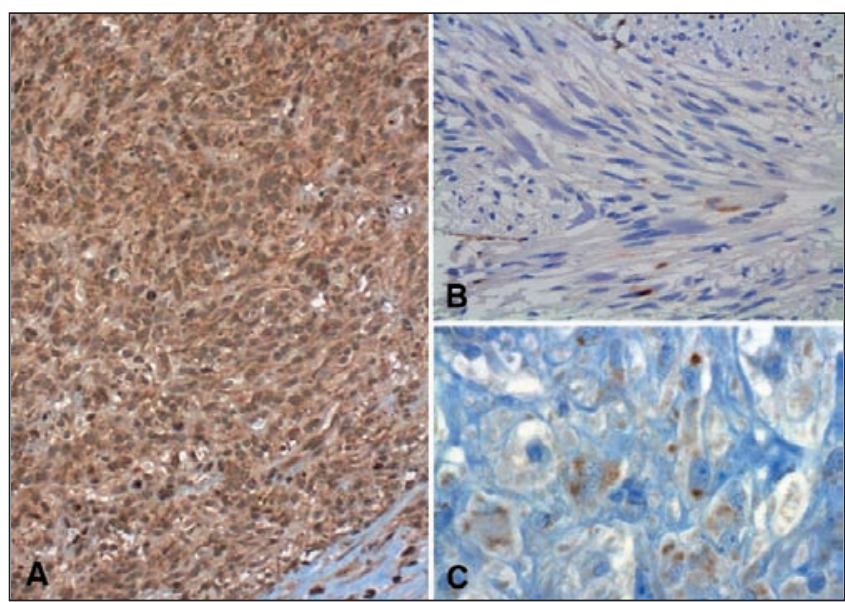

Fig. 3. GIST. PDGFRA staining pattern. A. Cytoplasmic and membrane staining in tumor with epithelioid phenotype. B and C. Cytoplasmic and paranuclear Golgi-like staining in an epithelioid tumor.

association of this pattern with exon 11 mutations and with homozygosis status, but these findings have not been confirmed $(8,9)$. In the present series, a statistically-significant association was observed between the Golgi-like pattern and KIT mutations, affecting not only exon 11 but also -in three cases-KIT exon 9.

The existence of tumors with morphological and clinical features similar to those of GISTs but staining negative for CD117 highlights the limitations of this antibody as a universal marker for GISTs. Although negative staining may be attributable to focal expression (e.g. in small biopsies) or to technical constraints (deficient fixation, prolonged storage, technical error), molecular biology techniques have shown that staining may be negative even in tumors with KIT or PDGFRA either ab initio or in the course of tumor progression (26). Moreover, congenital GISTs, which are morphologically indistinguishable from adult GISTs, are typically CD117-negative $(27,28)$; this

Table IV. Mutational status and CD117/PDGFRA expression

\begin{tabular}{|c|c|c|c|c|c|c|}
\hline & $\begin{array}{l}\text { Exon } 11 \\
\text { KIT }\end{array}$ & $\begin{array}{l}\text { Exon } 9 \\
\text { KIT }\end{array}$ & $\begin{array}{l}\text { Exon } 18 \\
\text { PDGFRA }\end{array}$ & $\begin{array}{l}\text { Exon } 12 \\
\text { PDGFRA }\end{array}$ & $\begin{array}{l}\text { wt KITI } \\
\text { PDGFRA }\end{array}$ & Total \\
\hline $\begin{array}{l}\text { CD117/ } \\
\text { PDGFRA }\end{array}$ & $n(\%)$ & $n(\%)$ & $n(\%)$ & $n(\%)$ & $n(\%)$ & \\
\hline$+/+$ & $\begin{array}{l}54 / 82 \\
(66 \%)\end{array}$ & $\begin{array}{l}3 / 82 \\
(4 \%)\end{array}$ & $\begin{array}{l}7 / 82 \\
(8.5 \%)\end{array}$ & $\begin{array}{l}1 / 82 \\
(1 \%)\end{array}$ & $\begin{array}{l}17 / 82 \\
(20.5 \%)\end{array}$ & $\begin{array}{l}82 / 86 \\
(96 \%)\end{array}$ \\
\hline$+/-$ & $\begin{array}{l}7 / 11 \\
(63 \%)\end{array}$ & $\begin{array}{l}1 / 11 \\
(10 \%)\end{array}$ & $\begin{array}{l}0 / 11 \\
(0 \%)\end{array}$ & $\begin{array}{l}0 / 11 \\
(0 \%)\end{array}$ & $\begin{array}{l}3 / 11 \\
(27 \%)\end{array}$ & $\begin{array}{l}11 / 13 \\
(80 \%)\end{array}$ \\
\hline$-/+$ & $\begin{array}{l}1 / 4 \\
(25 \%)\end{array}$ & $\begin{array}{l}0 / 4 \\
(0 \%)\end{array}$ & $\begin{array}{l}2 / 4 \\
(50 \%)\end{array}$ & $\begin{array}{l}1 / 4 \\
(25 \%)\end{array}$ & $\begin{array}{l}0 / 4 \\
(0 \%)\end{array}$ & $\begin{array}{l}4 / 86 \\
(5 \%)\end{array}$ \\
\hline$-/-$ & $\begin{array}{l}2 / 2 \\
(100 \%)\end{array}$ & $\begin{array}{l}0 / 2 \\
(0 \%)\end{array}$ & $\begin{array}{l}0 / 2 \\
(0 \%)\end{array}$ & $\begin{array}{l}0 / 2 \\
(0 \%)\end{array}$ & $\begin{array}{l}0 / 2 \\
(0 \%)\end{array}$ & $\begin{array}{l}2 / 13 \\
(15 \%)\end{array}$ \\
\hline
\end{tabular}


contrasts with findings reported for pediatric GISTs, which are mostly CD117-positive (3). Molecular analysis of apparently CD117-negative GISTs is therefore recommended. An early study of CD117-negative GISTs (29) found that most originated in the stomach, mesentery or epiploon, had epithelioid cell morphology and displayed the following molecular profile: $72 \%$ had PDGFRA mutations, $16 \%$ had KIT mutations and $8 \%$ were wt KIT/PDGFRA. Later reports from less-selective studies note a significant increase in the number of CD117-negative tumors harboring KIT mutations $(17,30)$. In the present study, 50\% of CD117-negative tumors had KIT mutations, and the other 50\% PDGFRA mutations; almost all of them (5/6) originated in the stomach.

In the normal gastrointestinal tract, PDGFRA staining is found in colocalization with S100 in ganglion bodies, nerve fibers and Schwann cells (11). In GISTs, the PDGFRA staining pattern is variable; it may be either cytoplasmic, with or without membrane accentuation, or paranuclear (Golgi-like pattern), or a combination of the two. However, results reported in the literature indicate some disagreement: Rossi et al. (12) found that PDGFRA and KIT expression were mutually exclusive, and were indicative of mutations in these genes, whilst Pauls et al. (11), Peterson et al. (31) and Miselli et al. (9) reported that PDGFRA was ubiquitously expressed, though with certain variations. According to Pauls et al. (11), the Golgi-like staining pattern is found both in mutant (KIT or PDGFRA) and wild-type GISTs, but is more common in PDGFRAmutated tumors, whilst the cytoplasmic/membrane staining pattern is ubiquitous, irrespective of mutational status. Misselli et al. (9), however, report that the Golgi-like pattern is found only in tumors with PDGFRA mutations, whereas only the cytoplasmic/membrane pattern is observed in KITmutated and wild-type tumors; they also note that PDGFRA staining is less intense in KIT-mutated than in PDGFRAmutated tumors ( 21 vs. 92\%), whilst CD117 positivity is more intense in KIT-mutated GISTs (78 vs. 12\%); however, the tendency to express both markers is more marked in the latter. In the present series, both markers tended to be expressed in KIT-mutated tumors. The Golgi-like staining pattern was not exclusive to PDGFRA-mutated tumors, as suggested by Miselli et al. (9), although a statistically-significant association with them was observed; the results obtained here thus lend support to the findings reported by Pauls et al. (11).

In conclusion, expression of CD177 and PDGFRA is not mutually exclusive, while the presence of a Golgi-like staining pattern either for CD117 or for PDGFRA, though not exclusive, is significantly associated with mutations in the respective genes, and may therefore be considered highly suggestive of mutational changes. Caution must be exercised when using these findings as an indicator for therapy, since it is now known that certain KIT and PDGFRA mutations do not respond to imatinib therapy (PDGFRA Exon 18, Asp846Val; KIT exon 17, Asn822Lys) or do so only at higher doses (KIT, exon 9) (19).

\section{REFERENCES}

1. Miettinen M, Lasota J. Gastrointestinal stromal tumors. Review on morphology, molecular pathology, prognosis, and differential diagnosis. Arch Pathol Lab Med 2006;130:1466-78.

2. Kindblom LG, Remotti HE, Aldenborg F, Meis-Kindblom JM. Gastrointestinal pacemaker cell tumor (GIPACT): gastrointestinal stromal tumors show phenotypic characteristics of the interstitial cells of Cajal. Am J Pathol 1998;152:1259-69.

3. Agaram NP, Laquaglia MP, Ustun B, Guo T, Wong GC, Socci ND, et al. Molecular characterization of pediatric gastrointestinal stromal tumors. Clin Cancer Res 2008;14:3204-15.

4. Janeway KA, Kim SY, Lodish M, Nosé V, Rustin P, Gaal J, et al. Defects in succinate dehydrogenase in gastrointestinal stromal tumors lacking KIT and PDGFRA mutations. Proc Natl Acad Sci USA 2011;108:314-8.

5. Joensuu H, Roberts PJ, Sarlomo-Rikala M, Andersson LC, Tervahartiala P, Tuveson D, et al. Effect of the tyrosine kinase inhibitor STI571 in a patient with a metastatic gastrointestinal stromal tumor. N Engl J Med 2001;344:1052-6.

6. Dematteo RP, Heinrich MC, El-Rifai WM, Demetri G. Clinical management of gastrointestinal stromal tumor: before and after STI-571. Hum Pathol 2002;33:466-77.

7. Díaz-Delgado M, Hernández-Amate A, Sánchez-León M, PereiraGallardo S, Prieto-Sánchez E, Jiménez-Sáenz M, et al. Multiple nonmetastatic gastrointestinal stromal tumors. Differential features. Rev Esp Enferm Dig 2010;102:489-97.

8. Emile JF, Stock N, Corless CL, Sciot R, Schildhaus HU, Brahimi S, et al. Dotlike or Golgi-like KIT and PDGFRA staining in GIST. Am J Surg Pathol 2009;33:157-8.

9. Miselli F, Millefanti C, Conca E, Negri T, Piacenza C, Pierotti MA, et al. PDGFRA immunostaining can help in the diagnosis of gastrointestinal stromal tumors. Am J Surg Pathol 2008;32:738-43.

10. Negri T, Orsenigo, M, Conca E, et al. Dotlike or Golgi-like KIT and PDGFRA staining in GIST. Am J Surg Pathol 2009;33:158-9.

11. Pauls K, Merkelbach-Bruse S, Thal D, Büttner R, Wardelmann E. PDGFR alpha and c-kit-mutated gastrointestinal stromal tumours (GISTs) are characterized by distinctive histological and immunohistochemical features. Histopathology 2005;46:166-75.

12. Rossi G, Valli R, Bertolini F, Marchioni A, Cavazza A, Mucciarini C, et al. PDGFR expression in differential diagnosis between KIT-negative gastrointestinal stromal tumours and other primary soft-tissue tumours of the gastrointestinal tract. Histopathology 2005;46:522-31.

13. Mazur MT, Clark HB. Gastric stromal tumors. Reappraisal of histogenesis. Am J Surg Pathol 1983;7:507-19.

14. Markku M, Lasota J. Gastrointestinal stromal tumors: definition, clinical, histological, immunohistochemical, and molecular genetic features and differential diagnosis. Virchows Arch 2001;438:1-12.

15. Demetri GD. Differential properties of current tyrosine kinase inhibitors in gastrointestinal stromal tumors. Semin Oncol 2011;38(Supl. 1): S10-9.

16. Heinrich MC, Corless CL, Demetri GD, Blanke CD, von Mehren M, Joensuu H, et al. Kinase mutations and imatinib response in patients with metastatic gastrointestinal stromal tumor. J Clin Oncol 2003;21: 4342-9

17. Debiec-Rychter M, Wasag B, Stul M, De Wever I, Van Oosterom A, Hagemeijer A, et al. Gastrointestinal stromal tumours (GISTs) negative for KIT (CD117 antigen) immunoreactivity. J Pathol 2004;202:430-8.

18. Debiec-Rychter M. Sunitinib -a new approach following failure of imatinib in patients with advanced gastrointestinal stromal tumor-. Nat Clin Pract Oncol 2007;4:342-3.

19. Lasota J, Miettinen M. Clinical significance of oncogenic KIT and PDGFRA mutations in gastrointestinal stromal tumours. Histopathology 2008;53:245-66.

20. Miettinen M, Sobin LH, Sarlomo-Rikala M. Immunohistochemical spectrum of GISTs at different sites and their differential diagnosis with a reference to CD117 (KIT). Mod Pathol 2000;13:1134-42.

21. Kirsch R, Gao Z-H, Riddell R. Gastrointestinal stromal tumors. Diagnostic challenges and practical approach to differential diagnosis. Adv Anat Pathol 2007;14:261-85.

22. Hirota S, Isozaki K, Moriyama Y, Hashimoto K, Nishida T, Ishiguro $\mathrm{S}$, et al. Gain-of-function mutations of c-kit in human gastrointestinal stromal tumors. Science 1998;279:577-80. 
23. Wasag B, Debiec-Rychter M, Pauwels P, Stul M, Vranckx H, Oosterom AV, et al. Differential expression of KIT/PDGFRA mutant isoforms in epithelioid and mixed variants of gastrointestinal stromal tumors depends predominantly on the tumor site. Mod Pathol 2004;17:889-94.

24. Kang HJ, Nam SW, Kim H, Rhee H, Kim NG, Kim H, et al. Correlation of KIT and platelet-derived growth factor receptor alpha mutations with gene activation and expression profiles in gastrointestinal stromal tumors. Oncogene 2005;24:1066-74.

25. Corless CL, Heinrich MC. Molecular pathobiology of gastrointestinal stromal sarcomas. Annu. Rev Pathol Mech Dis 2008;3:557-86.

26. Pauwels P, Debiec-Rychter M, Stul M, De Wever I, Van Oosterom AT, Sciot R. Changing phenotype of gastrointestinal stromal tumours under imatinib mesylate treatment: a potential diagnostic pitfall. Histopathology 2005;58:41-7.

27. Bates AW, Feakins RM, Scheimberg I. Congenital gastrointestinal stromal tumors is indistinguishable from the adult form, but does not express
CD117 and carries a favourable prognosis. Histopathology 2000;37: 316-22.

28. Geramizadeh B, Bahador A, Ganjei-Azar P, Asadi A. Neonatal gastrointestinal stromal tumor. Report of a case and review of literature J Pediatr Surg 2005;40:572-4.

29. Medeiros F, Corless CL, Duensing A, Hornick JL, Oliveira AM, Heinrich MC, et al. KIT-negative gastrointestinal stromal tumors proof of concept and therapeutic implications. Am J Surg Pathol 2004;28: 889-94.

30. Motegi A, Sakurai S, Nakayama H, Sano T, Oyama T, Nakajima T PKC theta, a novel immunohistochemical marker for gastrointestinal stromal tumors (GIST), especially useful for identifying KITnegative tumors. Pathol Int 2005;55:106-12.

31. Peterson MR, Piao Z, Weidner N, Yi ES. Strong PDGFRA positivity is seen in GIST but not in other intra-abdominal mesenchymal tumors: Immunohistochemical and mutational analysis. Appl Immunohistochem Mol Morphol 2006;14:390-6. 